\title{
An Empirical Investigation on the Impact of Quality Management on Productivity and Profitability: Associations and Mediating Effect
}

\author{
Arawati Agus \\ Graduate School of Business \\ Universiti Kebangsaan Malaysia \\ E-Mail: araa@pkrisc.cc.ukm.my \\ Mhd.Suhaimi Ahmad \\ Faculty of Economics and Business \\ Universiti Kebangsaan Malaysia \\ E-Mail:mhsuh@pkrisc.cc.ukm.my \\ Jaafar Muhammad \\ Faculty of Economics and Business \\ Universiti Kebangsaan Malaysia \\ E-Mail: mohamadj@pkrisc.cc.ukm.my
}

\begin{abstract}
This paper tries to investigate on how quality management practices may affect productivity and profitability in the electronics and electrical industry. This study attempts to fill the research gap by examining relationships between quality management practices, productivity and profitability in the electronics and electrical industry using correlation, multiple regression analyses and SEM. In doing so, relationships between QM, productivity and profitability constructs were assessed and described. The results reveal that quality measurement, benchmarking in particular as well as employee focus, supplier relations and training appear to be of primary importance and exhibit significant impact toward productivity and profitability. In addition, the findings also suggest that productivity mediates the link between QM and profitability. Findings of the study provide a striking demonstration of the importance of quality management practices for the electronics and electrical industry in Malaysia in enhancing its productivity and profitability.
\end{abstract}


Keywords: Quality Management, Productivity, Profitability, Electronics and Electrical Industry, Correlation, Multiple Regression and SEM

\section{INTRODUCTION}

Manufacturing companies in Malaysia have never had it so tough. After having to contend with the recent economic crisis, they are now confronting with increasing prices of oil and raw materials, high interest rates, high advancement in innovation and technology as well as high customer expectation on the quality of products and services. Given the competitive pressures, many manufacturing companies continuously seek ways to improve quality. Quality of a product or service is the degree to which the product or service meets specifications and needs of customers. Quality management $(\mathrm{QM})$ is a concept based on continuous improvement in the performance of processes in an organization and in the quality of the products and services that are the outputs of those processes. It is a team activity, demands a new culture, emphasis and it calls for discipline and quality knowledge. Quality advocates have identified several critical principles for successful QM practices which among others are: top management commitment, customer focus, supplier relationship, benchmarking, quality-oriented training, employee focus, zero-defects, process improvement and quality measurement (Saraph et al, 1989).

Top management acts as the main driver for QM implementation, creating values, goals and systems to satisfy customer expectations and to improve an organization's performance (Ahire et al., 1996). A customer focus keeps the business aware of the changes taking place in its environment and provides the knowledge needed to change the product. Likewise, benchmarking is another process in which an organization continuously compares and measures itself against business leaders anywhere in the world to gain information and provide a guideline for rational performance goals (Boone \& Wilkins, 1995). As of late, it has been widely accepted that the most valuable resource within a company is the people that work within it (employee focus). Furthermore, people in the organization should be continually trained and be given adequate training and education on prescriptions, methods and the concept of quality, which usually includes QM principles, team skills, and problem solving (quality related training). Setting a goal of zero defects, and continuing to renew one's commitment to moving ever closer toward that goal, will lead to improvements that continue to approach absolute perfection over time (Richman \& Zachary, 1993). Simultaneously, process improvement requires everyone 
in an organization to work towards doing things right the first time, every time. This requires process ownership, process documentation, defined customer and supplier requirements, indicators and measurement criteria, an improvement methodology and the necessary statistical methods (Anonymous, 1995). Lastly, quality measurement is a goal-orientation with constant performance measurement, often with the use of statistical analysis. The analysis process ensures that all deviations are appropriately considered, measured and responded to consistently (Shores, 1992).

This paper explores the possibility of adopting QM as the basis for enhancing productivity and profitability in the electronics and electrical industry in Malaysia. First, this paper proceeds with a brief explanation on the QM principles and literature review; second, it discusses the methodology adopted, the objectives of the study and the test conducted to obtain the reliable measures of QM variables; third, it determines the correlations between QM, productivity and profitability; fourth, it highlights the results of correlations, regression and SEM analyses; and finally, the results are then discussed and implications for academics and practitioners highlighted.

\section{LITERATURE REVIEW}

The research literature on QM has identified numerous studies across the world. It is said that QM has the potential to not only increase competitiveness and organizational effectiveness but also improve product quality and organizational performance (Ahire et al., 1996; Opara, 1996; Bayazit \& Karpak, 2007; Ortiz et al., 2006). Specifically, Powell (1995) raised a series of questions regarding the relationship between QM and performance. He suggests that there are significant relationships between QM, competitive advantage and business performance. In addition, several studies have succeeded in providing evidence that TQM has a positive impact on financial performance and/or overall performance (Schaffer \& Thompson, 1992; Opara, 1996; Cherkasky, 1992; Agus \& Hassan; 2000; Bayazit \& Karpak, 2007; Kaynak, 2003; Ortiz et al., 2006). Agus (2001) found that training and top management commitment play very important roles in TQM implementations in public listed manufacturing companies. The overall findings of that study point to the significant and positive impact of QM on competitive advantage and customer satisfaction, which, in turn, significantly improves the financial performance of these companies. On the other hand, Deming (1986) argued that improvements in quality do create corresponding improvements in productivity by reducing costs, errors, rework, and delays. 
Empirically, the purpose of this study is also to present an explicit result on the relationship between QM, productivity and profitability where other researchers have perhaps known or describe them only implicitly. There are studies which suggest that QM improves performance but, with a few exceptions, rarely support it with statistical evidence. This study is one of few attempts to estimate the effects of implementing QM programs. It fills a gap that exists in the literature on QM in the electronics and electrical industry in Malaysia.

\section{RESEARCH METHODOLOGY}

The instrument used in this study was a structured survey questionnaire, which was designed to assess the companies in term of the described dimensions. The sample chosen for this study were manufacturing companies in the electronics and electrical industry in Malaysia. Sample companies were randomly chosen from a list of electronics and electrical companies in Klang Valley, Malaysia. Companies in Klang Valley were chosen because the majority of electronics and electrical companies were situated in Klang Valley (the fastest growing areas situated in Kuala Lumpur, Selangor and part of neighbouring states). Reasons for focusing on this sector are twofold. First, electronics and electrical has emerged as a leading sector in Malaysia in terms of adopting new manufacturing and quality practices and these practices are driven primarily by competitive rather than regulatory forces. Second, the industry is heterogeneous in terms of sub-sectors and product/process complexity. The electrical and electronics (E\&E) industry has played important roles in the development of the manufacturing sector in Malaysia and contribute major portions of national export. In 2005, percentage export from E\&E industry was about three quarter of total manufacturing export at 65.8 per cent (Ministry of Finance, 2004). However, the emergence of AFTA, NAFTA, and European Union (EU) in tandem with trade liberalization has an impact on Malaysian trade in terms of stiffer competition with other countries in the world. In this study, one hundred and fourteen useable responses were received and were analyzed using the SPSS package. The primary objective of this study is to measure senior quality managers' or production manager's perception of quality management practices and level of productivity and profitability in the industry. Face to face interviews with quality managers or production managers were carried out to ensure information accuracy, validating the outcome of analysis and developing an understanding of practical aspects of quality management principles adoption. 
The instrument developed in this study consists of two major parts. The first part comprises several constructs measuring QM practices, and the second part comprises performance measurements. To enable respondents to indicate their answers, 7-point interval scales were use for the questionnaire. A total of nine constructs of QM, which have been widely referred, were extracted. Given the scarcity of research in Malaysia that examines associations between QM, productivity and profitability, the purpose of this paper is to enhance managerial understandings of quality management practices, productivity and profitability. The main objectives of this paper are:

- To empirically investigate correlates between QM, productivity and profitability.

- To empirically assess the importance of each QM indicator on productivity and profitability.

- To empirically determine whether productivity mediates the link between QM and profitability.

Nine key indicators of QM with a total of 40 original items were extracted. The critical variables of quality management in this study had content validity because an extensive review of the literature was conducted in selecting the measurement items and the critical factors, and all the items and factors were evaluated and validated by professionals in quality areas. The QM variables in this study were adopted from prominent studies or sources (Powell 1995, Saraph et al. 1989, Deming 1986, Juran 1992, Crosby 1979 and Malcolm Baldridge 1992). As the initial data analysis, the nine constructs were subjected to validity and reliability tests before a single score can be calculated to represent each construct. In order to obtain reliable measures, a reliability test was conducted to determine the item analysis and internal consistency and stability of the measurements (Churchill, 1979). The reliability analysis was conducted by calculating the Cronbach's alpha for each scale. The result shows that the Cronbach's alpha measure for the nine constructs exceeds the threshold point of 0.70 suggested by Nunnally (1978). Alpha coefficients for QM scales range between 0.8435 and 0.9628 after the alpha maximization process were carried out.

\section{RESEARCH HYPOTHESES}

The main purpose of the study is to investigate the relationship between QM, productivity and profitability. On the basis of the literature, the study hypothesizes directional relationship between QM, productivity and ultimately profitability. In addition, the study investigates whether productivity mediates the linkage between 
QM and profitability. Three hypotheses for this study are stated as follows: Hypothesis 1: QM practices are positively correlated with productivity Hypothesis 2: QM practices are positively correlated with profitability Hypothesis 3: Productivity mediates the linkage between QM and profitability.

\section{PRELIMINARY RESULTS: CORRELATIONS}

Table 1 Correlations between Quality Management Practices, Productivity and Profitability

\begin{tabular}{|c|l|c|c|}
\hline \multicolumn{2}{|c|}{ Quality management practices } & Productivity & Profitability \\
\hline 1 & Top Management Commitment & $0.499^{* *}$ & $0.376^{* *}$ \\
\hline 2 & Customer Focus & $0.509^{* *}$ & $0.370^{* *}$ \\
\hline 3 & Supplier Relations & $0.524^{* *}$ & $0.296^{* *}$ \\
\hline 4 & Training & $0.558^{* *}$ & $0.305^{* *}$ \\
\hline 5 & Employee Focus & $0.475^{* *}$ & $0.465^{* *}$ \\
\hline 6 & Benchmarking & $0.635^{* *}$ & $0.585^{* *}$ \\
\hline 7 & Zero Defects & $0.468^{* *}$ & $0.316^{* *}$ \\
\hline 8 & Process Improvement & $0.451^{* *}$ & $0.380^{* *}$ \\
\hline 9 & Quality Measurement & $0.730^{* *}$ & $0.595^{* *}$ \\
\hline & $*$ P $\leq 0.05, * *$ P $\leq 0.01 \quad 2 . \quad$ All t-tests are one-tailed \\
\hline
\end{tabular}

Pearson's correlation analysis was conducted to investigate relationships between QM practices, productivity and profitability. This result indeed confirms the close associations between these constructs. Productivity and profitability have significant correlations with top management commitment, supplier relations, training, employee focus, benchmarking, zero defect, process improvement and quality measurement (H1 and H2). These findings are consistent with several previous studies that proclaimed better organizational transformations as a result of QM initiatives (Bayazit \& Karpak, 2007; Kaynak, 2003; Ebrahimpour \& Withers, 1992; Bowen \& Lawler, 1992; Ortiz et al., 2006). In an effort to improve productivity and profitability, an electronics or electric company should obtain the support of top management, secure high quality supplies, train employees in quality related activities, implement benchmarking, ensure zero defects, enhance process improvement and standardized quality measurement. 


\section{DETERMINING QUALITY MANAGEMENT LINK TO PRODUCTIVITY AND PROFITABILITY: MULTIPLE LINEAR REGRESSION ANALYSES}

In this study, multiple regression analyses were conducted to identify most important quality management practices and to investigate the relationship between a set of predictor variables and a dependent variable (Black, 2001). In this paper, two models were developed to represent an attempt to account for the contributions of critical determinants of QM on profitability and productivity.

\section{Testing the Overall Regression Model}

The overall significance of the multiple regression models are tested with the following hypotheses.

$H_{0}: \beta_{1}=\beta_{2}=\beta_{3}=\beta_{4}=\beta_{5} \ldots \beta_{i}=0$

$H_{a}$ : At least one of the regression coefficients is $\neq 0$.

Table 2 Regression Summaries

\begin{tabular}{|c|c|c|c|c|c|c|c|}
\hline Model & $\begin{array}{c}\text { Dependent } \\
\text { Variable }\end{array}$ & $\mathrm{R}$ & $\mathrm{R}^{2}$ & Adjusted $\mathrm{R}^{2}$ & $\begin{array}{c}\text { Std Error } \\
(\mathrm{SE})\end{array}$ & $\mathrm{F}$ & $\mathrm{Sig}$ \\
\hline $\begin{array}{c}\text { First } \\
\text { Model }\end{array}$ & Productivity & 0.772 & 0.596 & 0.584 & 0.924 & 52.05 & 0.00 \\
\hline $\begin{array}{c}\text { Second } \\
\text { Model }\end{array}$ & Profitability & 0.704 & 0.496 & 0.477 & 1.214 & 25.81 & 0.00 \\
\hline
\end{tabular}

A rejection of the null hypothesis indicates that at least one of the predictor variables is adding significant predictability for the dependent variable. Two multiple regression analyses were conducted where the first model had productivity as the dependent variable and the second model highlighted profitability as the dependent variable. Briefly, multiple stepwise regression analyses indicated that strong relationships between constructs existed for both model. The first model (Table 2) which highlights the impact of quality management practices on productivity, has a good fit and significantly high values of $\mathrm{R}(0.772)$ as well as $R^{2}(0.596$ and a significant F-value of 52.052. The model exhibits a significant $F$ value. The model suggested that three quality management practices (quality measurements, benchmarking and training) were able to explain almost $60 \%$ of the variation in the dependent variable (productivity). The second model (Table 2) which presents the relationship between quality management practices and profitability, has a good fit and has significantly high values of $\mathrm{R}(0.704)$ and $R^{2}(0.496)$ with standard error of 
1.214 and a significant F-value of 25.806. The model suggests that four quality management practices (quality measurements, benchmarking, supplier relations and employee focus) are able to explain almost $50 \%$ of the variation in the dependent variable (profitability). This value is considered quite high, given the multitude of factors affecting profitability (Stevens 1986).

\section{Significance Tests of the Individual Regression Coefficients}

Table 3 The Relationship between Quality Management Practices and Productivity: A Stepwise Regression Analysis (The first model)

\begin{tabular}{|l|l|l|l|l|c|}
\hline $\begin{array}{c}\text { Quality Management } \\
\text { practices }\end{array}$ & \multicolumn{2}{|c|}{ Std. Coefficient } & Std. & $\mathrm{t}$ & Sig. \\
\cline { 1 - 3 } & Beta & S. Error & Beta & & \\
\hline Constant & 0.244 & 0.443 & & 0.552 & 0.582 \\
\hline Quality Measurement & 0.520 & 0.094 & 0.481 & 5.546 & 0.000 \\
\hline Benchmarking & 0.217 & 0.077 & 0.237 & 2.834 & 0.006 \\
\hline Training & 0.194 & 0.088 & 0.169 & 2.209 & 0.029 \\
\hline
\end{tabular}

Dependent variable $=$ Productivity.

Testing the regression coefficients using t-tests not only gives researchers some insight into the fit of the regression model, but it also helps in assessing the strength of individual predictor variables in estimating the dependent variable (Hair et al. 1995, Black, 2001). The result in Table 3 indicates that regression coefficients or slopes of QM variables especially quality measurement, benchmarking and training have significant impacts on productivity. In addition, the findings (Table 4) also indicate that regression coefficients or slopes of quality measurement, benchmarking, supplier relations and employee focus have significant contributions toward profitability. These findings further support the alternate hypotheses that these regression coefficients or slopes are significantly different from zeros and have predictive powers in estimating productivity or profitability.

Table 4 The Relationship between Quality Management Practices and Profitability: A Stepwise Regression Analysis (The Second Model)

\begin{tabular}{|l|l|l|l|l|l|}
\hline $\begin{array}{c}\text { Quality Management } \\
\text { practices }\end{array}$ & \multicolumn{2}{|c|}{ Std. Coefficient } & Std. & $\mathrm{t}$ & Sig. \\
\hline & Beta & S. Error & Beta & & \\
\hline Constant & 1.146 & 0.667 & & 1.717 & 0.089 \\
\hline Quality measurement & 0.534 & 0.120 & 0.423 & 4.470 & 0.000 \\
\hline Benchmarking & 0.383 & 0.110 & 0.357 & 3.478 & 0.001 \\
\hline Supplier Relations & 0.462 & 0.146 & 0.304 & 3.176 & 0.002 \\
\hline Employee focus & 0.340 & 0.108 & 0.270 & 3.153 & 0.002 \\
\hline
\end{tabular}

Dependent variable $=$ Profitability . 


\section{THE MEDIATING EFFECT OF PRODUCTIVITY ON THE QUALITY MANAGEMENT AND PROFITABILITY LINKAGE}

Having found that there are significant relationships between QM and productivity as well as QM and profitability, the question is now directed at examining whether productivity mediates the relationship between QM and profitability (Baron \& Kenny, 1986; Judd \& Kenny, 1981). In testing the mediating effects, QM scales were substituted by a single variable, obtained from the mean of these scores.

Table 5 The Mediating Effect Of Productivity On QM And Profitability Linkage

\begin{tabular}{|c|c|c|c|c|}
\hline Independent & Mediating & \multicolumn{3}{|c|}{ Beta Coefficients } \\
\cline { 3 - 5 } Variable & Variable & Model 1 & Model 2 & Model 3 \\
\hline $\begin{array}{c}\text { Mean Quality } \\
\text { Management }\end{array}$ & Productivity & $0.564^{*}$ & $0.729^{*}$ & $\begin{array}{c}0.168 \\
\text { (ns) }\end{array}$ \\
\hline
\end{tabular}

Regression analyses were conducted separately to test the mediating effect of productivity on the QM and profitability linkage (Table 5). Model 1 shows the relationship between $\mathrm{QM}$ and profitability without the inclusion of productivity (Mediator). Model 2 exhibits the relationship between QM and the mediator (productivity), where the mediator is treated as the outcome variable. Model 3 is the mediating regression that shows the relationship between QM and profitability with the inclusion of the mediating variable (productivity). For the mediating effect to exist, the value of beta coefficient of QM in Model 3 should be lesser than the value of the slope in Model 1. The results indicate that the beta coefficient of QM with the inclusion of productivity in Model 3 has a lower value than in Model 1. Since the beta coefficient in Model 3 is not significant (statistically equal to zero) and lesser value (0.168) than the beta coefficient of the independent variable in Model 1 (0.564), we can suggest that productivity has a full or complete mediating effect on the linkage between QM and profitability (H3).

In addition, the author also conducted a structural equation modeling (SEM) analysis to further support the proposition that productivity mediates the relationship between QM and Profitability (H3). Using SEM, the strength of the relationships between QM practices, productivity and profitability were examined simultaneously. In the initial stage, Confirmatory factor analysis (CFA) was conducted on the constructs. Confirmatory factor analysis (CFA) or a measurement model using AMOS 5 was employed for examining construct validity of each scale by assessing how well 
the individual item measured the scale (Ahire, Golhar, and Walter 1996). The goodness of fit indices (GFI) of all the constructs exceeded the 0.90 criterion suggested by Hair et al. (1995), hence, establishing the structural validity. The latent construct QM is being represented by the three most important and significant QM variables namely quality measurement (mdqmeas), benchmarking (mdbench) and training (mdtrain). Meanwhile the latent mediating construct, productivity is being described by two manifest variables, improvement in productivity (prodtvt) and production efficiency (proeffic). Lastly, the latent endogenous construct profitability is represented by revenue growth (revgrow) and profits (profit). In SEM statistical analysis, we would like the model developed to fit the data, therefore the acceptance of the null hypothesis of the overall model is expected. Hence, in this test of goodness of fit for the SEM, the probability we are looking for should be higher than 0.05 . The result indicates that the Chi-square value is 15.172 with $p$-value of 0.232 (Figure 1). The result suggests that the model has a good fit. The p-value is considerably sufficient ( $p$-value $>0.05$ ) in supporting the proposition that the overall model fits the data. Furthermore, other statistical structural indices such as Goodness of fit index GFI (0.964), Bentler comparative fit model CFI (0.995) and Normed fit index NFI (0.976) further suggest that the model has a satisfactory fit (Table 6). Since the probability value and structural modeling indices are well above the recommended level, the model is considered to be a reasonable representation of the data (Hair et al., 1995). The direct structural effect of QM on productivity is high (0.889). The standardized structural coefficient of QM on productivity is associated with low standard error (0.208) and non-zero critical ratio (6.619), which indicates that the structural effect between these two constructs is positive and the relationship is significant. In addition, productivity also exhibits strong and positive structural effect on profitability (0.803), with low standard error $(0.103)$ and significant critical ratio (10.242). Therefore, we have enough evidence to accept the proposition that productivity mediates the link between $\mathrm{QM}$ and profitability (H3). As such, it is essential to reaffirm that $\mathrm{QM}$ can enhance productivity and ultimately improve profitability of the electronics and electrical industry in Malaysia. 
Standardized estimates

Chi-square=15.172

Degree of Freedom $=12$

Probability $=.232$

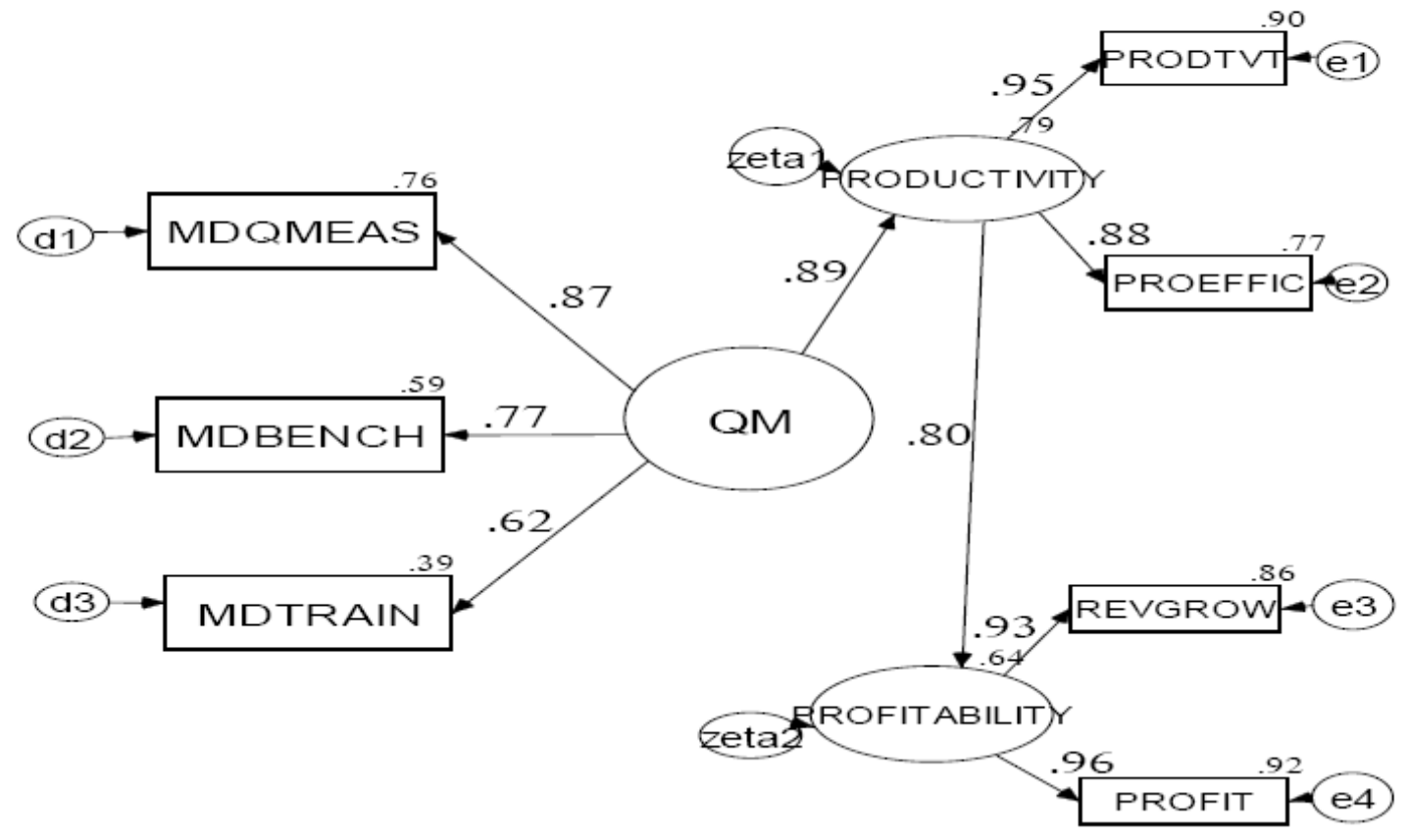

Figure 1 The Structural Equation Model Showing the Mediating Effect of Productivity in The QM and Profitability Link

\section{CONCLUSION AND IMPLICATIONS}

QM provides a vision that focuses everyone in an organization on quality improvement. The pursuit of quality improvement is not only requested by the market but also driven by the need to survive. Manufacturers must make quality products better, faster, and cheaper than those of their competitors. Adoption of effective quality management strategies will be one of the most crucial factors for success in the electronics and electrical industry. Overall, we can suggest that quality management practices have positive impact on productivity and profitability.

In summary, the findings of the empirical study are clear, and suggest several things. Firstly, we can say that quality measurement, employee focus, supplier 
relations, benchmarking and training have strong contributions toward QM implementations. Secondly, there is significant impact of QM on productivity and profitability of the Malaysian electronics and electrical industry. This study also found a significant mediating effect of productivity on the QM and profitability link. That is, higher level of QM implementation would lead to higher level of productivity and ultimately higher level of profitability.

Table 6 Goodness of Fit Indices and Measurement Model

\begin{tabular}{|l|l|c|}
\hline \multicolumn{1}{|c|}{ Statistics } & $\begin{array}{l}\text { Model } \\
\text { Values }\end{array}$ & $\begin{array}{l}\text { Recommended } \\
\text { values for good fit }\end{array}$ \\
\hline Chi square & 15.172 & - \\
\hline Probability Level & 0.232 & $\geq 0.05$ \\
\hline Degree of Freedom & 12 & - \\
\hline$\chi^{2} /$ df & 1.264 & $\leq 3.00$ \\
\hline $\begin{array}{l}\text { Bentler (1990) comparative fit model } \\
\text { (CFI) }\end{array}$ & 0.995 & $\geq 0.90$ \\
\hline Normed fit index (NFI) & 0.976 & $\geq 0.90$ \\
\hline Goodness of fit index (GFI) & 0.964 & $\geq 0.90$ \\
\hline
\end{tabular}

*Chau (1997)

The conclusion emerging from this study is that QM will ultimately result in positive gains. The results validate some of the key linkages and support beliefs and evidence by researchers of the relationship between QM, productivity and profitability. Quality makes manufacturing process efficient, and productivity is the ratio of output over input (Rothman, 1994). QM can lead to decreased waste, rework and ultimately to a variety of related improvements. It is aimed at improving processes, eliminating mistakes, and satisfying customers (customer focus). No doubt quality and productivity go hand in hand. Nonetheless, continuous improvement in quality and productivity must be matched by profits. Continuous improvement for total customer satisfaction should be an integral part of the way a manufacturing company conducts its business. It is very important that a company determine what the customer wants and needs because they determine the sales and ultimately profitability (Blanchard, 1994). After all, involving employees, empowering them, and bringing them into the decision-making process provide the opportunity for continuous process improvement. The untapped ideas, innovations, and creative thoughts of employees can make the difference between success and failure (Besterfield et al., 1995). However, to enhance their knowledge and skill requires training. Finally, another approach to quality improvement is to engage in 
benchmarking. This involves studying, and attempting to emulate, the strategies and practices of organizations already known to generate world-class products and services (Weiers, 2005).

It is also important to note that this study attempts to enrich the literature review and make a contribution in quality-related studies. The purpose is obvious, to make it explicit what other researchers have perhaps known implicitly. The empirical results support long-standing beliefs and anecdotal evidence by researchers about the relationships between $\mathrm{QM}$, productivity and profitability, and lend credibility to causal hypotheses that improving quality in processes and practices leads to improvements in external performance results. This study to some extent helps in resolving controversy about measurements of performance gains from implementing QM. By strengthening QM practices, improved performance will likely to occur. This result provides evidence that improving internal practices will positively impact the most important performance measures.

The paper will be of particular interest to practicing managers as it suggest what factors should be emphasized to stimulate the adoption of quality management concepts with their limited resources. The result indicates that electronics and electrical companies should emphasize greater attention to the quality management aspects of the manufacturing process and a greater degree of management support for quality programs such as quality measurement and benchmarking. On top of that, education and training are also important in preparing an organization for a change, in accomplishing the change itself, and institutionalizing it as a permanent part of the organization.

\section{REFERENCES}

Ahire, S.L.,Golhar, D. Y. \& Waller, M. A. (1996). Development and validation of QM implementation constructs. Decision Sciences, 27(1), 23-55.

Anonymous. (1995). ISO and Total Quality. International Journal of Health Care Quality Assurance, 8(4), 34-35.

Agus, A \& Hassan, Z. (2000). Exploring the relationship between the length of QM adoption and financial performance: An empirical study in Malaysia. International Journal of Management, 17(3), 323-333.

Agus, A. (2001). A linear Structural Modelling of Total Quality Management Practices in Manufacturing Companies in Malaysia. Total Quality Management, 12(5), 561-573. 
Baron, R. M., \& Kenny, D. A. (1986). The moderator-mediator variable distinction in social pychological research: Conceptual, Strategic and statistical considerations. Journal of Personality and Social Psychology, 51, 1173-1182.

Bayazit, Ozden \& Karpak, Birsen (2007). An analytical network process-based framework for successful total quality management (TQM): An Assessment of Turkish manufacturing industry readiness. International Journal of Production Economics , 105, 79-96.

Black, K. (2001). Business Statistics: Contemporary decision-making. USA: SouthWestern College Publishing, Thompson Learning.

Blanchard, Ken . (1994). Competitive Trends, Executive Excellence. March.

Bowen, D., \& Lawler, L. (1992). Total quality-oriented human resource management. Organizational Dynamics, 24(4), 39-41.

Bentler, Peter M. (1990) Comparative fit indexes in structural models. Psychological Bulletin , 102(2), 238-246.

Besterfield, D. H., C. Bester-Michna, G. H. Besterfield, and M. Besterfield-Sacre. (1995). Total quality management. 2nd ed. Englewood Cliffs, N.J.: Prentice Hall.

Boone, E. Louis \& Wilkins, Dianne. (1995). The Role of Benchmarking in Total Quality Management. International Journal of Management, 12(1),123-131.

Chau, P.Y.K, (1997). Reexamining a model for evaluating information center success using a structural equation modeling approach. Decision Sciences, 28(2), 309334.

Cherkasky M., Stanley. (1992). Total Quality for a Sustainable Overall Service Performance. Quality, 13(8), 47-48.

Churchill, Gilbert A. Jr. (1979). A Paradigm for Developing Better Measures of Marketing Constructs. Journal of Marketing Research, 16(2), 64-73.

Cronbach, L.J. (1951). Coefficient Alpha and the Internal Structure of Tests. Psychometrika, 16, 297-334.

Crosby, P.B. (1979). Quality is free. London : Penguin Books Ltd.

Deming, W.E. (1986). Out of crisis: Quality, productivity and competitive position. Cambridge: Cambridge University Press.

Ebrahimpour, M., \& Withers, B.E. (1992). Employee involvement in quality improvement: A comparison of American and Japanese manufacturing firms operating in the U.S.. IEEE Transactions on Engineering Management, 39(2), 142-148.

Hair, J.F., Anderson, R.E., Tatham, R.L. \& Black, W.C. (1995). Multivariate data analysis, Englewood Cliffs. NJ: Prentice-Hall. 
Judd, C. M. \& Kenny, D. A. (1981). Process analysis: Estimating mediation in treatment evaluations. Evaluation Review, 5, 602-619.

Juran, J.M. (1992). Juran on quality by design: The new steps for planning quality into goods and services. New York: Free Press. Macmillan, Inc.

Kaynak, Hale. (2003). The relationship between total quality management practices and their effects on firm performance. Journal of Operations Management, 21(2003), 405-435.

Malcom Baldrige (1992). National quality award application guidelines. Gaithersburg, USA: National Institute of Standards and Technology.

Ministry of Finance Malaysia. (2004). Economic Report, 2004-2005: Kuala Lumpur: Government Publication.

Nunnally, J. (1978). Psychometric Theory. New York: Mc Graw Hill Book Co.

Opara, Emmanuel Uzoma. (1996). The Empirical Test of Total Quality Management: An Application of QM at Chevron and Its Impact on Productivity. Quality Management Journal, 4(1), 10.

Ortiz, J.P., Benito, J.G. \& Galende, J. (2006). Total quality management as a forerunner of business innovation capability. Technovation, 26(10) , 1170-1185.

Powell, Thomas C. (1995) Total Quality Management as overall service performance: A Review and Empirical Study. Strategic Management Journal, 16, 15-37.

Richman, Eugene \& Zachary, William. (1993). Quality and Reliability Management: Review and Update. Quality Management, 35(4), 8-11.

Rothman, Howard. (1994). Quality's Link to Productivity, Nation's Business, February, 33-34.

Saraph, Jayant V., Benson, George P., \& Schroeder, Roger G. (1989). An Instrument for Measuring the Critical Factors of Quality Management. Decision Sciences, 20, 810-829.

Schaffer, R H \& Thompson H. (1992). Successful Change Programs Begin with Results. Harvard Business Review, September/October, 80-89

Shores, Richard, A. (1992). Improving the Quality of Management. Systems Quality Progress, June, 53-57.

Stevens, J. (1986). Applied multivariate statistics for the social sciences. Hillsdale, NJ: Lawrence Erlbaum Associates

Weiers, R. M. (2005). Introduction to Business Statistics. Belmont, USA: Thompson Brooks/Cole. 
